African Journal of Educational Studies in Mathematics and Sciences Vol. 15, No. 2., 2019

\title{
Understanding problem identification in research using analogies
}

\author{
K. K. ${ }^{1}$ Oyediran
}

\begin{abstract}
Problem in a research as well as human body calls for perfect diagnosis of illness. This is important to avoid treating the symptoms instead of the actual disease. A research problem could be identified through professional or/and academic efforts. This poses a lot of problems to students, both at the undergraduate and postgraduate levels, as this determines the title of their articles or research works. Many of them have to submit many topics to their supervisors before one could be reframed and approved. At times, students appealed to their supervisors to provide them with researchable topics. This to the supervisor(s) almost writing the dissertations/theses for them. The argument of this paper is to let students understand "problem identification" using an analogy from the Holy Bible. The study employed a conversation analysis methodology, which is empirically grounded, exploratory in process and inferential. This involves using every conversation between two or more parties to explore facts/lesson. It was recommended that seasoned lecturers should explain to students how to identify research problems using what are familiar to them to make them understand this important aspect of research.
\end{abstract}

Keywords: research problem identification; understanding problem identification; analogy in research

\section{Introduction}

A problem or a problematic situation in any community (urban or rural) is firstly felt before it could be referred to as a problem. A situation becomes a problem if it affects a person, a group of people or/and a community as a whole. A problem is an issue that apparently needs to be interpreted as matter needing change in order for the problem to be solved (Jonker and Pennink, 2010). These authors explained further that problematisation is all about the process in which people perceive, elaborate, interpret, frame and label a situation in such a way that it is called 'a problem' which could be summarised as the process in which people formulate or create a problem.

According to Baird (2009), analogy means an inductive form of argument that asserts that if two or more entities are the same in one or more respects, then there is a probability that they will be similar in other respects. The author expatiates that analogies could be of different types and used for many purposes such as literary analogies used to paint vivid word pictures, scientific analogies used for explanatory purposes and in philosophy, Plato illustrated his ideas by the use of welldeveloped analogies. In another instance, Bacon (2009) adopts making inferences with analogy by drawing from the characteristics or properties of the larger group to which that datum belonged. The author submits that the method of making inferences from analogies adds significantly to the improvement of scientific hypotheses and is regarded as a fundamental advancement of the scientific method.

\footnotetext{
${ }^{1}$ Kayode Kunle Oyediran is in the Department of Urban \& Regional Planning, College of Environmental Studies, Waziri Umaru Federal Polytechnic, Birnin-Kebbi, Nigeria. Email: oyediran.kay2011@yahoo.com; or Kunle Oyediran < diran4kay@gmail.com
}

\footnotetext{
Open Access article distributed under the terms of the Creative Commons Attributions License [CC BY-NC-ND 4.0] http://creativecommons.org/licenses/by-nc-nd/4.0. DOI: https://dx.doi.org/10.4314/ajesms.v15i2.3
} 
The identification and analysing of a research problem is the first and most crucial step of research process. Singh (2006) establishes that a problem cannot be solved effectively unless a researcher possesses the intellect and insight to isolate and understand the specific factors giving rise to it. During problem identification stage, "a problem must be identified as a candidate for research and evaluated to assess its suitability before resources are allocated to pursuing it" (Thomas 2004, p. 26). In any research settings, problem identification might involve studying the problem, defining it from a number of perspectives, using different theoretical frameworks to investigate it, and having different and opposing viewpoints to solving it (Cunningham, 1993).

This paper aims at making researchers understand identification of problem in research using an analogy. It has the following sections: introduction, statement of the problem, literature review, analogy of the case between Lazarus and the rich man, methodology, findings and discussion, conclusion and recommendations.

\section{Statement of the Problem}

There is a lot of literature on statement of the research problem. Bryman (2007) writes on purposes of a problem statement, Fischler (n. d) presents the flow of ideas in the problem statement and the types, Simon (n. d) focuses on the content of a problem statement, Process Improvement Unit (n. d) states how to write a problem and Singh (2006) writes on the importance of problem statement. All the reviewed literature focus on content of problem statement, its purpose/importance and how to write it. The gap of understanding/identifying the research problem has not been filled or very little has been done on it in the literature. Meanwhile, nobody could write successfully on what $\mathrm{s} / \mathrm{he}$ does not understand. The person might end up in writing irrelevance because $\mathrm{s} / \mathrm{he}$ would be ignorance of the contents, and the purpose may not be understood. In another vein, experience in academics has shown that identification of research problems and statement of research problem are usually the first issues to discuss with students before approving their topics. Evidence that many students do not understand the problem they want to solve manifests when they submit their research topics or titles. Many of them submit between three (3) and six (6) topics/titles before one of them is approved or the supervisor ends up giving or suggesting one. This act leads to writing of all or part of the dissertation/thesis by the supervisor him/ herself. Therefore, this aspect has to be handled properly using every means to make sure that students or researchers understand this. Based on this, this paper aims at letting students/researchers understand problem identification in research through a biblical analogy.

\section{Literature Review}

A problem could be viewed as a puzzle that needs a solution or an unfavourable situation that requires a serious attention (Fischler, n. d). A research problem is a clear expression (statement) about an area of concern, a difficulty to be eliminated, a condition to be improved upon, or a troubling question that exists in scholarly literature, in theory, or within existing practice that points to a need for meaningful understanding and deliberate investigation (Bryman, 2007). In the opinion of Singh (2006), a research problem is spelt out by the topic, which pin points the task of a researcher and requires a researcher to learn/know how to recognise the problem. It is on this note that the author proffers some steps to identifying a research problem. These steps are presented in Box 1. 
Step 1: Determining the area of research that a researcher is keen to do the research work.

Step 2: The researcher should develop the mastery on the area or it should be the area of his specialisation.

Step 3: He should review researches conducted in the area to know the recent trend and studies in the area.

Step 4: Based on review, he should consider the priority field of the study.

Step 5: He should draw an analogy and insight in identifying a problem or employ his personal experience of the field in locating the problem. He may take help of supervisor or expertee of the field.

Step 6: He should pinpoint specific aspect of the problem, which is to be investigated.

Source: Singh (2006: p. 23)

\section{Box 1: Steps to follow in identifying a research problem}

Fischler (n. d) opines that research problem is an area of conflict, concern, or controversy (a gap between what ought to be and what is in existence) that requires reviewing the most relevant literature to support the claim. Fischler (ibid) further points out three important reasons for a research problem. These include problem:

i. It establishes the importance of the topic.

ii. It creates reader interest.

iii. It focuses the reader's attention on how the study will add to the literature.

At this juncture, it should be noted that identification of a problem includes research topic selection and the statement of the problem. To them, topic selection or statement of the problem and research problem are synonymous (Singh, 2006).

As regards source(s) of a suitable research problem, Singh (2006) having stated that the selection of a suitable problem is not an easy task, recommends the sources in Box 2 as suitable ones. The sources in Box 2 are six (6) in number and each points to different areas of sourcing for a problem. 
1. Personal experiences of the researcher are the main source for identifying suitable problem.

2. Another source of problem, which is most frequently used by researchers/students and popularly suggested by supervisors, is the extensive study of available literature-research abstracts, journals, government gazettes and handbooks on research. He can draw an analogy for selecting a research problem or can think parallel problem in the field studied.

3. In the choice of a suitable problem, the researcher should decide his field of investigation (regional planning, transportation, rural development, infrastructural planning, urban design and planning and housing). He should study the field intensively in the specific area; this may enable him to identify a problem from the specific field.

4. Innovations, technological changes and curricular developments are constantly bringing new problems and new opportunities for social studies, environmental and engineering researches.

5. The simplest and most common source of problem is to consult supervisor, experts of the field and most experienced person of the field. They may suggest most significant problem of the area. He can discuss certain issues of the area to emerge a problem. This is against the argument of this paper as it seems that other person is thinking for the students/researchers.

6. It common to some researchers that at the end of their works suggest some areas that require further researches.

Source: Singh (2006: p. 24)

Box 2 The main sources to which one may proceed for a suitable research problem

From the foregoing, three facts are common to all submissions or opinions in the literature. These include:

i. A research problem is an area that requires a solution.

ii. It is an important aspect of any research.

iii. Every researcher should learn how to recognise and define a problem because every other aspect of research relies on it.

Therefore, a research problem requires going beyond the physical if symptoms were not to be treated leaving the real disease/illness unattended to. Four important questions that should be answered to arrive at a problem in a research include:

i. What problem is your environment (atmosphere, lithosphere, hydrosphere and biosphere) or community passing through?

ii. Why is it a problem?

iii. How could it be solved?

iv. When could it be solved? (Process Improvement Unit, n. d).

In summary, a research problem could be academically or professionally sourced. Whatever the case may be, since identifying the exact nature and dimensions of a problem is of major importance in research work, one needs to understand what a problem is or understand problem concept. 


\section{Analogy of the case between Lazarus and the rich man}

In teaching His listeners how to treat the poor around them justly, Jesus Christ told them the story of Lazarus (a poor man) and a rich man in Luke chapter 16. According to Him, the rich man enjoyed himself while on earth but Lazarus was a beggar (with poor health and poverty) at the gate of this rich man. They both died and were buried. while the rich man landed in hell, Lazarus was at the bosom of Abraham (father of faith) enjoying himself. This rich man then made a request from Abraham: "Father Abraham, have pity on me and send Lazarus to dip the tip of his finger in water and cool my tongue, because I am in agony in this fire" (Luke 16:24). Abraham answered the rich man and said: ... between us and you there is a great gulffixed: so that they which would pass from hence to you cannot; neither can they pass to us, that would come from thence" (v.26).

\section{Methodology}

Data for this paper were sourced through secondary means that include review of some literature on problem identification and writing of the statement of problem in research. In addition, an extract was or extracts were made from the Holy Bible. Qualitative data were used throughout this work. That gave the author the opportunity to infer from the conversation between the rich man and Lazarus, and related it to problem identification in research. The collected data were analysed through conversation analysis, which is another approach that is considered qualitative. Deductions were made from every conversation. However, the name of the rich man was not mentioned in the analogy but an assumption that his name was Chief Andrew was made and nobody was targeted.

\section{Findings and Discussion}

Being a qualitative research, the conversation between the rich man (Chief Andrew) and Father Abraham were used as the data collected for this paper. These are presented as follows:

Chief Andrew: Father Abraham, have pity on me and send Lazarus to dip the tip of his finger in water and cool my tongue, because I am in agony in this fire.

Father Abraham:"... between us and you there is a great gulf fixed: so that they which would pass from hence to you cannot; neither can they pass to us, that would come from thence"

The impressive statement of Jonker and Pennink (2010) about a research problem is very relevant to this analysis as presented in Box 3.

"Is it really important to establish, for example, who is involved, what the problem's consequences are, the possible effect or impact of a solution and so forth and how the discrepancy between the 'current status' and 'desired status' is interpreted"'

Source: Jonker and Pennink (2010; p.9)

\section{Box 3: Statement about a research problem}

From Chief Andrew's words, it could be deduced that:

i. he was in a serious agony that required a serious intervention or solution.

ii. his current condition was unfavourable and unpleasant to him that he defined it as a problem.

iii. he desired a new status that would be conducive for him. 
K. K. Oyediran

All these were the contents of his request from Father Abraham. Chief Andrew identified his condition as a problem. So also, a group of people and community may face an undesirous, unfavourable and unpleasant situation or condition identified as a problem. The response of Father Abraham shows that:

i. neither Lazarus nor Chief Andrew could cross over.

ii. there was an obstacle (gulf)restricting them to where they were.

iii. unless the obstacle was removed, Chief Andrew would remain where he was with his problem.

\section{Remarks}

A research problem is a gap to be filled, an unanswered question to be solved, oral statement of what one has to achieve at the completion of the research. From the conversation between Father Abraham and Chief Andrew, the problem was an agony of thirsty in hell as identified by Chief Andrew. Therefore, in research, one could say that problem identification is a researcher's, product (man's product). This is because a problem is a problem to whom it is a problem. Those living with a problem might not identify it as a problem as there may be many people in hell but only Chief Andrew identified it as a problem.

The gulf mentioned by Father Abraham that was between them stands as the gap to be filled in research. This gap (gulf), that is required to be filled is between the messy/undesirous situation and the improved/desirous situation. This stands as the contribution of the present research to knowledge. This is pictorially expressed in Figure 1 as everybody wanted to get to top but could not because of the height restriction. The intervention of a rope fills the gap and connects those at basement to the top.

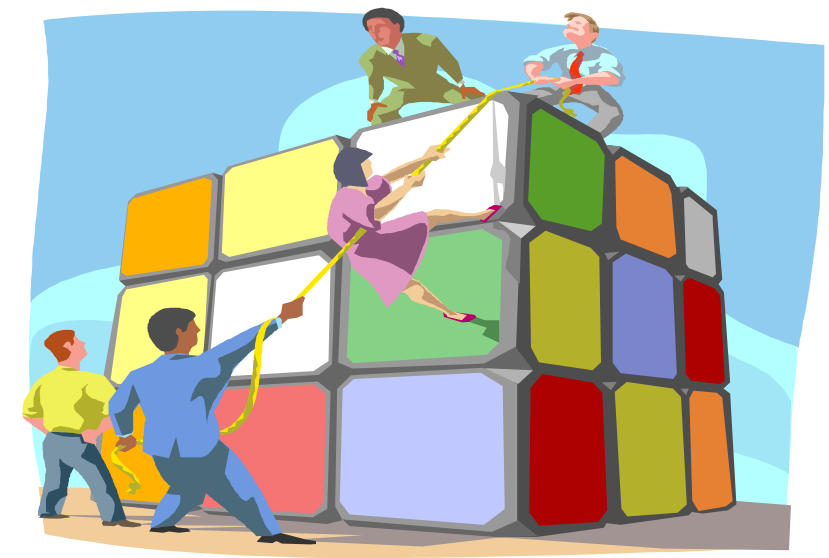

Figure1: $\quad$ Research Gap that Calls for Intervention Illustration

Source: Albino, 2009

In summary, it should be understood that in proper problem identification/formulation, three issues have to be considered. These are:

i. identification of problem as a messy situation that needs an improvement,

ii. the gap to be filled; and

iii. the new status or improved situation. 
It should be noted that if any of these issues were missing, it would affect the researcher's problem identification and lastly his conclusion.

\section{Conclusion}

Problem definition is the result of a reasoning process conducted by the researcher in order to translate the phenomenon to be examined into a (scientific) researchable (and relevant) research problem (Jonker and Pennink, 2010). These authors expatiate that a problem definition consists of both a research objective and a logically derived research question. These precisely establish what needs to be examined and why and under which (pre) conditions it should take place.

Although many suggestions already abound on writing research problem, all these suggestions are not ignored but one has to firstly understand how to identify a problem before knowing how to write it. To combat this situation, this paper has explained how to identify a problem through a Biblical analogy. It is the hope of the author that if potential researchers/project writers could understand this analogy, it would be easier for them to identify a problem and improve the quality of their researches.

\section{Recommendations}

A researcher's aim is to solve a problem through identification, examination and recommendation of ways of solving it. The first step in this order is problem identification that is the focus of this paper. Therefore, the following recommendations were made to make students understand how to identify problems in researches:

i. understanding a research problem and trashing it makes one a good researcher. Therefore, because of the importance of this aspect in research, supervisors as well as the lecturers handling Research Design and Methodology should employ what the students can see and hear to teach and illustrate research like the problem identification. To achieve this, the services of seasoned lecturers/supervisors are required.

ii. Lessons from other areas of life such as religion, tourism, recreation and so on could be linked to academic works just as it was done in this analogy. Thereby, students would know that learning does not stop in the classrooms only.

\section{References}

Albino, J. (2009).Community research utilities and support. Community and Behavioral Health, University of Colorado School of Public Health.

Bacon, F. (2009). Philosophers. Microsoft Encarta 2009 [DVD]. Redmond, WA: Microsoft Corporation, 2008.

Baird, R. M. (2008). Analogy. Microsoft Encarta 2009 [DVD]. Redmond, WA: Microsoft Corporation, 2008.

Bryman, A. (2007). The research question in social research: What is its role? International Journal of Social Research Methodology, 10: 5-20. https://libguides.usc.edu/writingguide

Cunningham, J. B. (1993). Action research and organizational development. Westport: Praeger Publishers.

Fischler, A. B. (n. d). From problem statement to research questions, School of Education, Nova Southeastern University. 
Understanding problem identification in research using analogies

K. K. Oyediran

Jonker, J and Pennink, B. W. (2010). The essence of research methodology: a concise guide for Master and PhD students in Management Science, London, Springer-Verlag Berlin Heidelberg

Process Improvement Unit (n. d). How to write a problem statement.www.piu@sheffield.ac.uk

Singh, Y. K. (2006). Fundamental of research methodology and statistics. New Delhi, New Age International Publishers Ltd.

Thomas, A. B. (2004). Research skills for management studies. London: Routledge. 